\title{
Scattering of Acoustic Waves from Ocean Boundaries
}

\author{
Marcia J. Isakson \\ Applied Research Laboratories \\ The University of Texas at Austin, TX 78713-8029 \\ phone: (512)835-3790 fax:(512)835-3259 email: misakson@arlut.utexas.edu \\ Award Number: N00014-12-1-0137 \\ http://www.arlut.utexas.edu
}

\section{LONG-TERM GOALS}

Development of a physical model of high-frequency acoustic interaction with the ocean floor, including penetration through and reflection from smooth and rough water/sediment interfaces, scattering from the interface roughness and volume heterogeneities and propagation within the sediment. The model will aid in the detection and classification of buried mines and improve SONAR performance in shallow water.

\section{OBJECTIVES}

1) Determination of the correct physical model of acoustic propagation through ocean sediments and scattering from sediment interfaces through the analysis of in situ measurements.

2) Development of predictive models that can account for the all of the physical processes and variability of acoustic propagation and scattering in ocean environments with special emphasis on propagation in shallow water waveguides and scattering from ocean sediments.

3) Development of the new experimental techniques to measure geo-acoustic parameters in the ocean.

\section{APPROACH}

1) Analysis of Acoustic Scattering for Layered and Poro-Elastic Ocean Sediments: Finite element (FE) analysis provides a noiseless testbed for the validation of approximate scattering models. In this case, perturbation theory and the Kirchhoff approximation were compared with an FE model on a layered and poro-elastic interfaces to ascertain the range of validity of the approximate models.

2) Longitudinally invariant and axi-symmetric propagation modeling for range dependent environments: Finite element propagation models are extended into three dimensions by taking a cosine transform for the out-of-plane wave number resulting in longitudinally invariant geometry and by considering a solution which is axi-symmetric. Both of these solutions were considered for range dependent geometries, one derived from experimental data and two canonical problems.

3) Bottom loss data collection at TREX13: Bottom loss data from $5-30 \mathrm{kHz}$ were collected as part of the Target and Reverberation Experiment 2013 (TREX13). These data were analyzed and an estimate of range dependent geoacoustic parameters were derived for the TREX reverberation site.

\section{WORK COMPLETED}

Analysis of Acoustic Scattering for Layered and Poro-Elastic Ocean Sediments: 


\section{Report Documentation Page}

Form Approved

OMB No. 0704-0188

Public reporting burden for the collection of information is estimated to average 1 hour per response, including the time for reviewing instructions, searching existing data sources, gathering and maintaining the data needed, and completing and reviewing the collection of information. Send comments regarding this burden estimate or any other aspect of this collection of information,

including suggestions for reducing this burden, to Washington Headquarters Services, Directorate for Information Operations and Reports, 1215 Jefferson Davis Highway, Suite 1204, Arlington

VA 22202-4302. Respondents should be aware that notwithstanding any other provision of law, no person shall be subject to a penalty for failing to comply with a collection of information if it

does not display a currently valid OMB control number.

\begin{tabular}{|c|c|c|}
\hline $\begin{array}{l}\text { 1. REPORT DATE } \\
\mathbf{3 0} \text { SEP } 2014\end{array}$ & 2. REPORT TYPE & $\begin{array}{l}\text { 3. DATES COVERED } \\
\mathbf{0 0 - 0 0 - 2 0 1 4} \text { to 00-00-2014 }\end{array}$ \\
\hline \multirow{3}{*}{\multicolumn{2}{|c|}{$\begin{array}{l}\text { 4. TITLE AND SUBTITLE } \\
\text { Scattering of Acoustic Waves from Ocean Boundaries }\end{array}$}} & 5a. CONTRACT NUMBER \\
\hline & & 5b. GRANT NUMBER \\
\hline & & 5c. PROGRAM ELEMENT NUMBER \\
\hline \multirow{3}{*}{\multicolumn{2}{|c|}{ 6. AUTHOR(S) }} & 5d. PROJECT NUMBER \\
\hline & & 5e. TASK NUMBER \\
\hline & & 5f. WORK UNIT NUMBER \\
\hline \multicolumn{2}{|c|}{$\begin{array}{l}\text { 7. PERFORMING ORGANIZATION NAME(S) AND ADDRESS(ES) } \\
\text { University of Texas at Austin,Applied Research } \\
\text { Laboratories,Austin,TX,78758 }\end{array}$} & $\begin{array}{l}\text { 8. PERFORMING ORGANIZATION } \\
\text { REPORT NUMBER }\end{array}$ \\
\hline \multirow{2}{*}{\multicolumn{2}{|c|}{ 9. SPONSORING/MONITORING AGENCY NAME(S) AND ADDRESS(ES) }} & 10. SPONSOR/MONITOR'S ACRONYM(S) \\
\hline & & $\begin{array}{l}\text { 11. SPONSOR/MONITOR'S REPORT } \\
\text { NUMBER(S) }\end{array}$ \\
\hline
\end{tabular}

12. DISTRIBUTION/AVAILABILITY STATEMENT

Approved for public release; distribution unlimited

13. SUPPLEMENTARY NOTES

14. ABSTRACT

15. SUBJECT TERMS

16. SECURITY CLASSIFICATION OF:

a. REPORT

unclassified b. ABSTRACT

unclassified c. THIS PAGE

unclassified
17. LIMITATION OF ABSTRACT

Same as

Report (SAR)
18. NUMBER 19a. NAME OF

OF PAGES RESPONSIBLE PERSON

9 
A finite element model was developed for scattering from layered ocean sediments. The model consisted of a tapered plane wave incident on either flat or rough interfaces. An example of the scattered pressure from a rough layered interface is shown in Fig. 1 for an plane wave incident field at 50 degrees grazing. In this case, the material in the lowest layer is elastic and can support a shear wave. Similar models were developed for poro-elastic interfaces. Note the interference pattern of the shear wave and compressional wave in the lowest layer. Also note the interference pattern in the intermediate fluid layer caused by multiple paths. The coherent reflection coefficient as a function of grazing angle is shown in Fig. 2 for this case. Note that due to resonances in the overlying fluid layer, the reflection coefficient has a large dip near 50 degrees grazing. This is seen in the scattered pressure picture in Fig. 1 as very little energy is reflected. In Fig. 2, the finite element result for cases in which the top interface only is rough and in which both are rough are compared with the reflection predicted by Eckart's theory [Eckart, 1953.], the Kirchhoff approximation (KA) [Ogilvy, 1991.] and the flat surface analytic solution. Note the large effect of scattering especially at normal incidence.

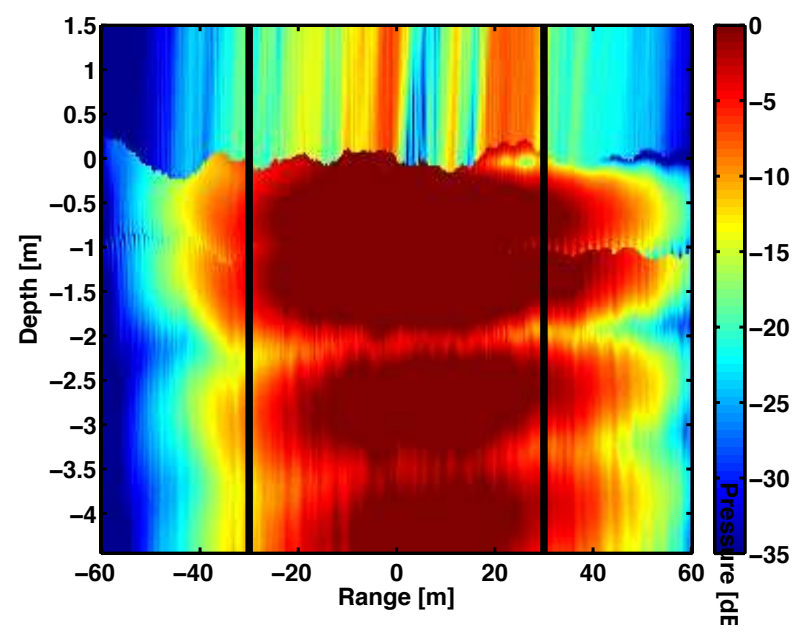

Figure 1: The magnitude of the pressure for a tapered plane wave at 50 degrees grazing incident on a interface consisting of a fluid layer overlying an elastic substrate.

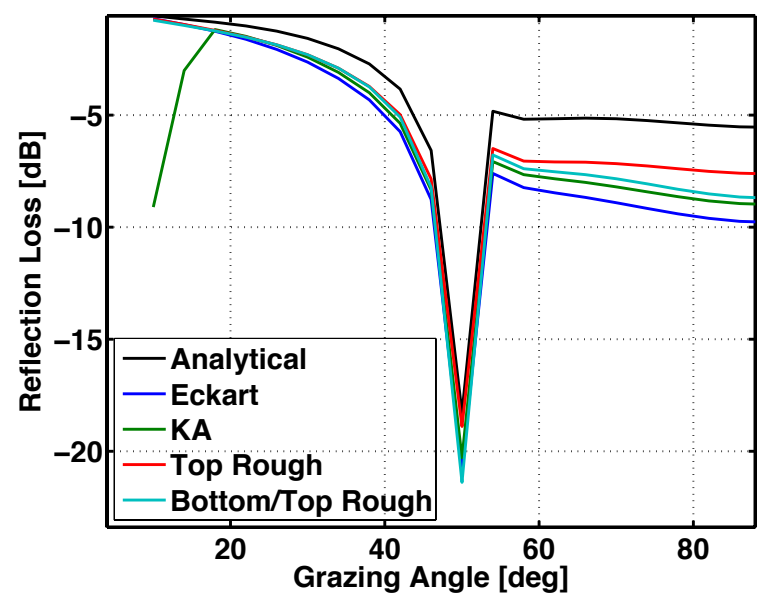

Figure 2: The reflection coefficient as a function of grazing angle for the case shown in Fig. 1, a fluid intermediate layer overlying an elastic basement. 
Longitudinally invariant and axi-symmetric propagation modeling for range dependent environments: The finite element propagation model was extended to domains with strong range dependence. In these models, the pressure was computed in three dimensions either by taking a cosine transform along one dimension resulting in longitudinal invariance or in assuming the geometry to be axially symmetric. An example of a range dependent, longitudinally invariant model is the canonical wedge shown in Fig. 3. The pressure field was calculated with finite elements and compared with a parabolic solution and an axi-symmetric FE model. The out of plane pressure picture is shown in the right panel of Fig. 2 and displays the expected out of plane diffraction and modal cutoff. These results can be compared with the results of Deane and Buckingham using an approximate ray theory model. [Deane, 1993.] Other range dependent models considered were a cosine hill, Gaussian canyon, and range dependent sediment variations derived from TREX measurements.
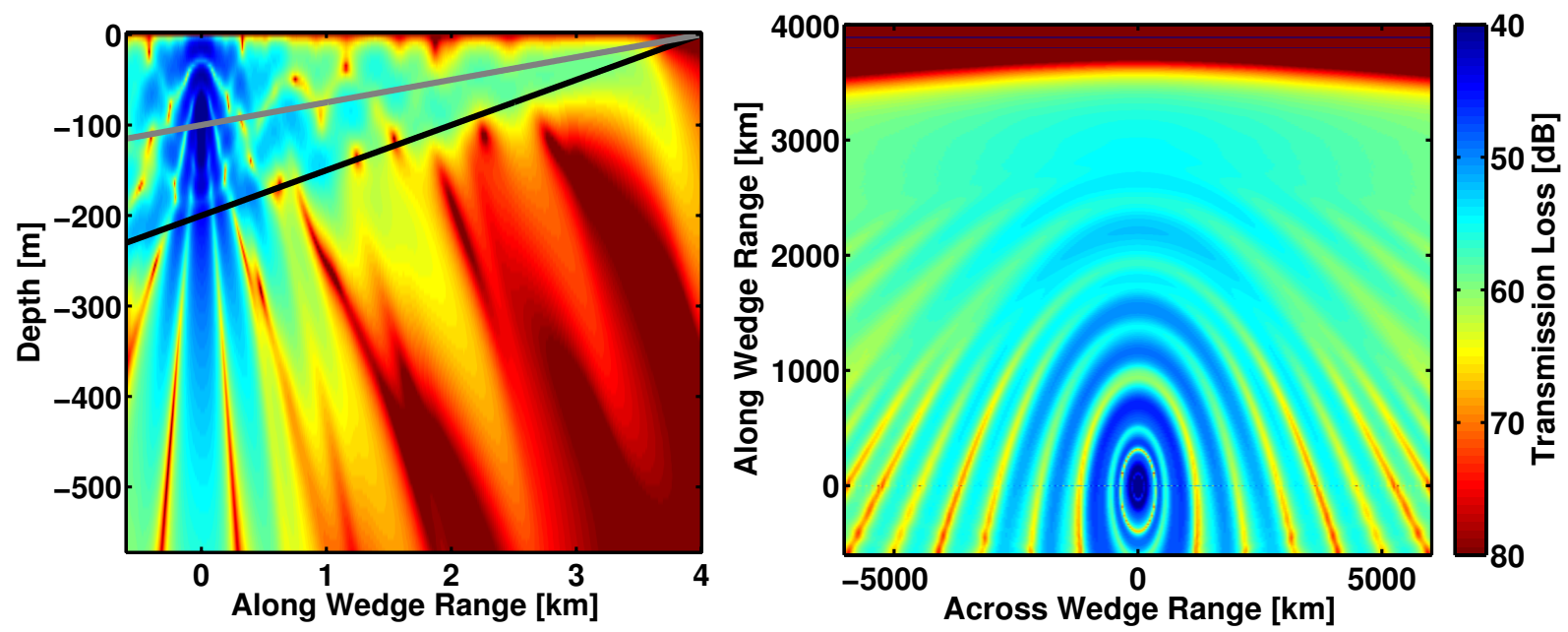

Figure 3: The magnitude of the pressure field of propagation in a wedge environment. The grey line in the left panel indicates the cut plane shown in the right panel.

Data Analysis and Modeling for TREX 2014:

Bottom loss data from $5-30 \mathrm{kHz}$ were collected along the TREX main reverberation path as shown in Fig. 4. Towing the ROV mounted acoustic system along the path collected these data. Overlayed on the bathymetry is multibeam sonar backscatter data. The colored circles correspond to some of the bottom loss data collected. The path was characterized by multibeam sonar by a series of "transition regions". These are evident in the in the multibeam data as lighter and darker stripes across the path. Along with data taken along the path, each transition region was further investigated by a series of measurements taken close to the ocean bottom. These data were taken concurrently with interface roughness measurements from the ARL:UT AUV mounted laser profiling system. An example of a transition region investigation is shown in the inset of Fig. 4. 


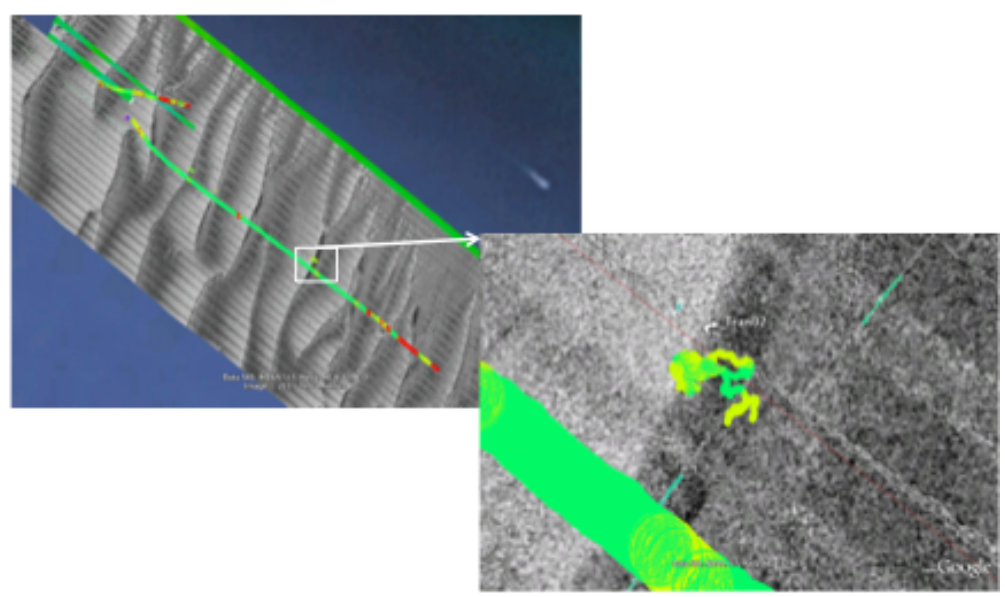

Figure 4: Location of portions of the bottom loss data taken at TREX13 by ARL:UT.

The matched filtered time series results are shown in the right panel of Fig. 5. Also shown is the expected arrival time of the bottom signal (green circles) and the peak return picked (black circle). The experiment was calibrated by inverting the apparatus in a tank and taking measurements from a flat air/water interface. Using this calibration, reflection coefficients were derived for the track over the reverberation path shown in Fig. 4. These data are shown in the left panel of Fig. 5.
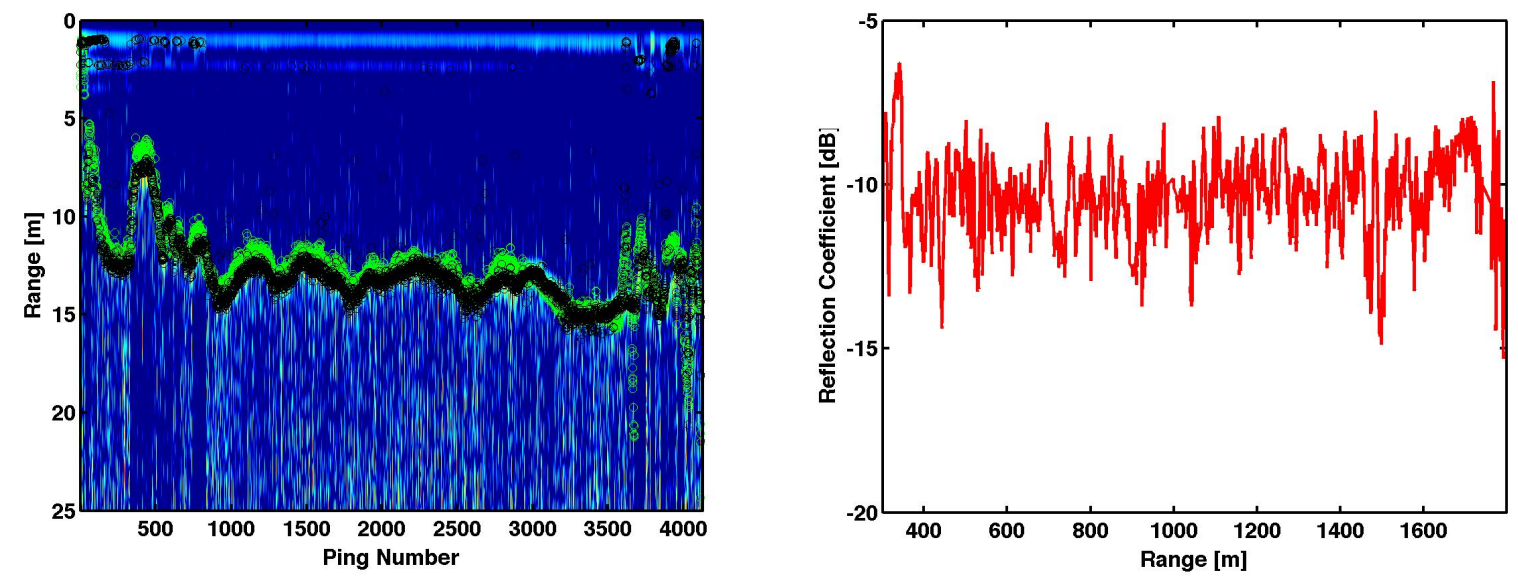

Figure 5: Examples of the matched filtered time series bottom loss data taken along the reverberation track (left) and derived reflection coefficients as a function of range along the reverberation track (right).

\section{RESULTS}

Analysis of Acoustic Scattering for Layered and Poro-Elastic Ocean Sediments:

The incoherent scattering cross section and angle dependent bottom loss was computed for the finite element scattering model and compared with several other models for layered ocean bottoms consisting of fluid layers and a fluid layer over an elastic substrate. The effect of the roughness of the bottom layer interface was investigated since many models including the GeoAcoustic Bottom Interaction Model (GABIM) only considers one rough interface. [Jackson, 2010.] The bottom loss 
comparison for the fluid over elastic layer is shown in Fig. 2. The comparison of both cases for backscattering is shown in Fig. 6. In both cases, results with only the top layer rough (bottom layer flat) are compared with both layers rough.

For both the fluid/fluid and fluid/elastic cases, perturbation theory and the Kirchhoff approximation agreed well with the finite element result. The only major difference was when the incident angle was at 50 degrees grazing in the fluid/elastic case. In this case, a resonance is excited in the fluid layer resulting in a very low reflection coefficient and high transmission through the first layer. At this angle, the effect of the bottom layer roughness is pronounced, and the finite element result deviates from the analytic predictions.
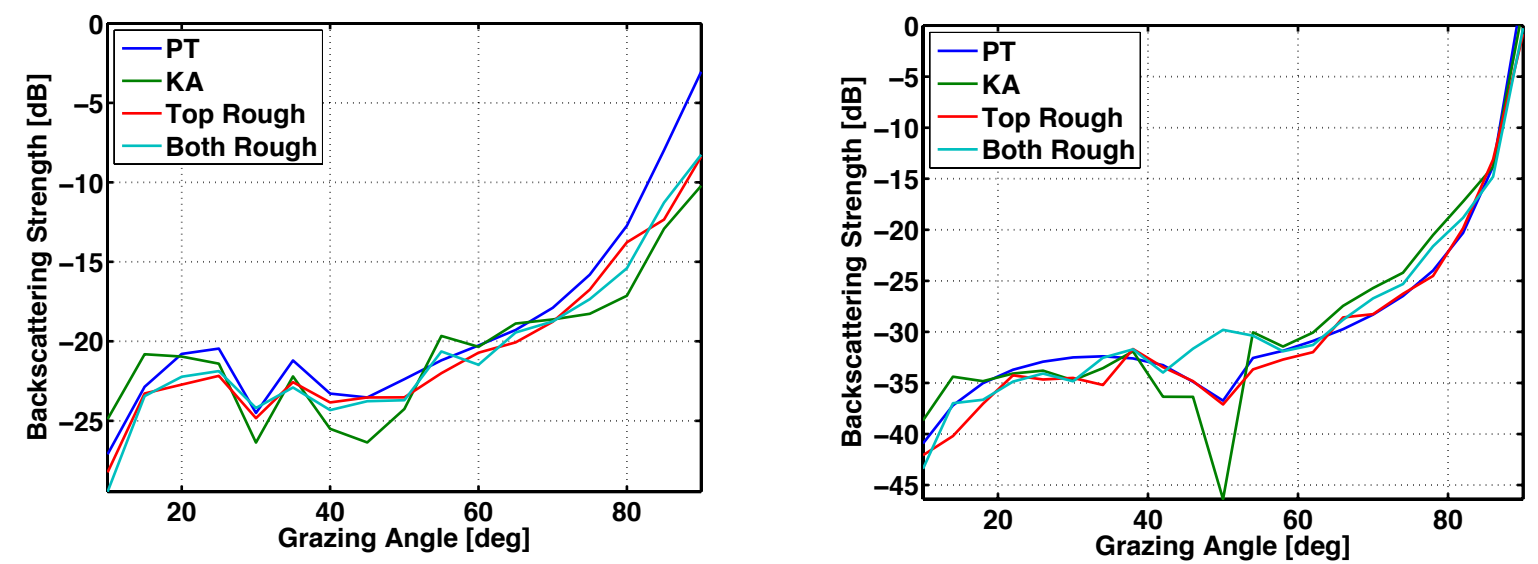

Figure 6: The backscattering strength for a layered bottom (left) and a fluid layer over an elastic substrate (right). Shown are the results from perturbation theory (blue), the Kirchhoff approximation (green), the finite element model with only the top layer layer rough (red) and both layers rough (cyan).

Lastly, the scattering cross section from roughened poroelastic sediment was compared with perturbation theory and the Kirchhoff approximation. An example result is shown in Fig. 7 . Full poroelastic theory is used in the finite element model while the effective density fluid model is used for perturbation theory. [Williams, 2001.] The closed form statistical Kirchhoff approximation is used with the reflection coefficient from full Biot theory. [Jackson, 2007.] In this case, the agreement among the models is good although the difference in the structure should be further investigated. 


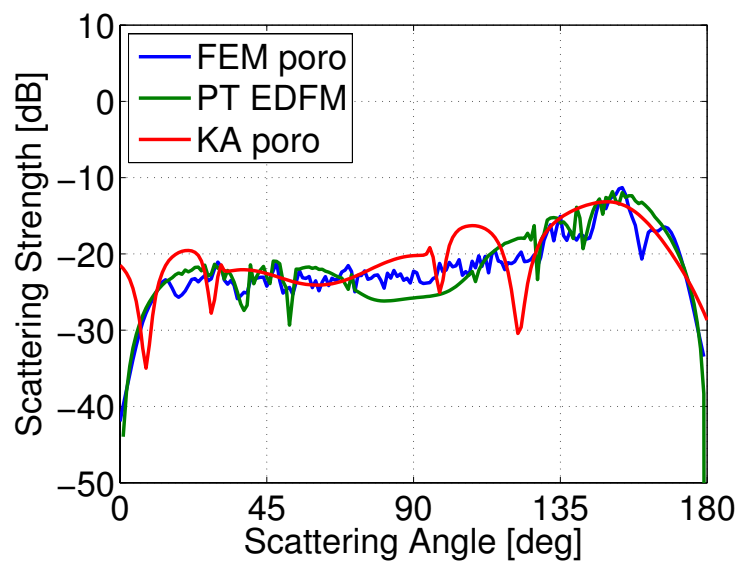

Figure 7: Comparison of the finite element scattering cross section for a poro-elastic bottom (blue) with perturbation theory based on the effective density fluid model (green) and the Kirchhoff approximation (red).

Longitudinally invariant and axi-symmetric propagation modeling for range dependent environments: In addition to the wedge environment, the longitudinally invariant finite element model was computed for propagation over a Gaussian canyon. The environment is described in [Tolstoy, 2001.] Cuts perpendicular to the canyon and parallel in depth are shown in Fig. 8 and Fig. 9 respectively. Threedimensional effects are clearly visible.

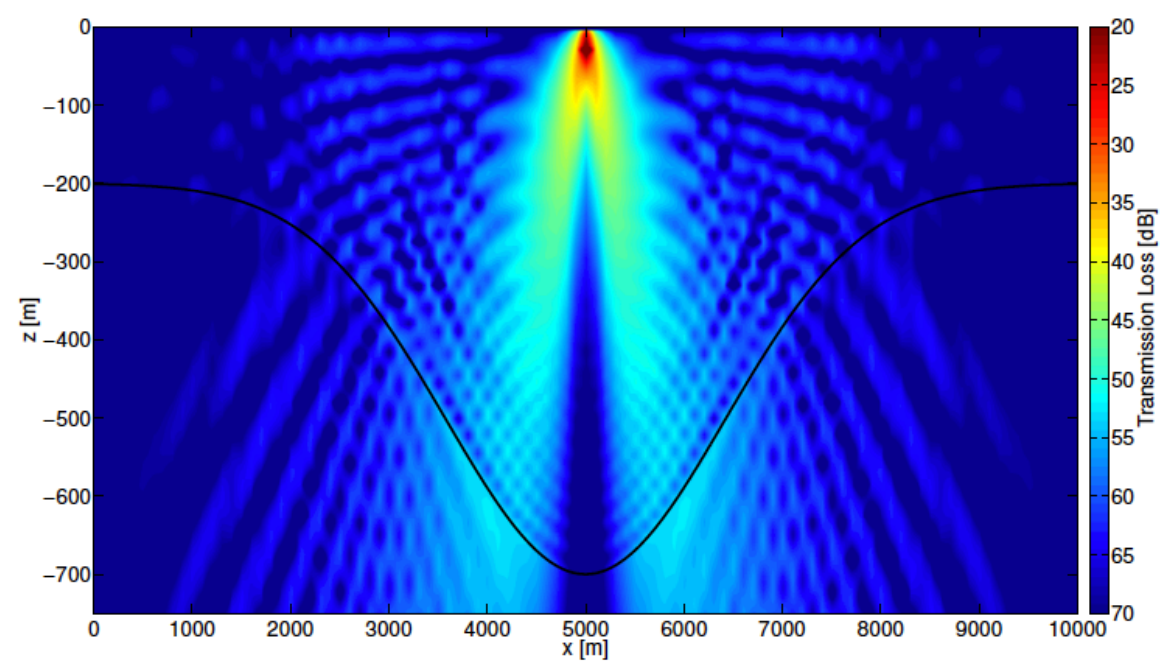

Figure 8: Perpendicular cut at the source point over a Gaussian canyon. 


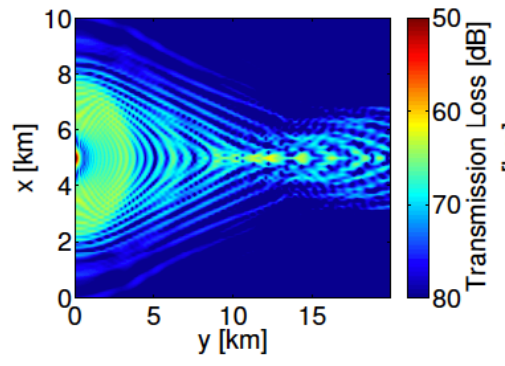

(a)

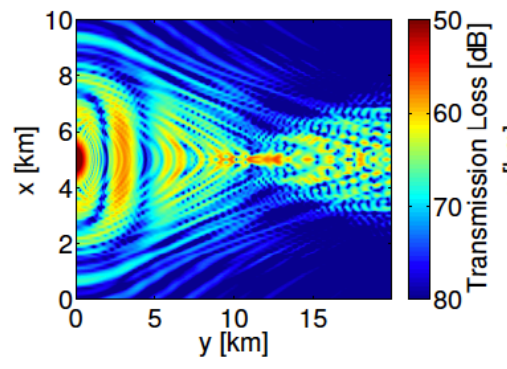

(c)

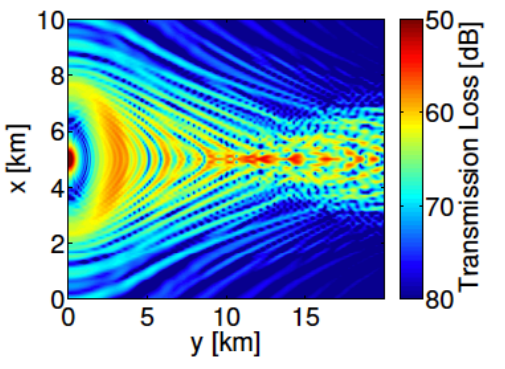

(b)

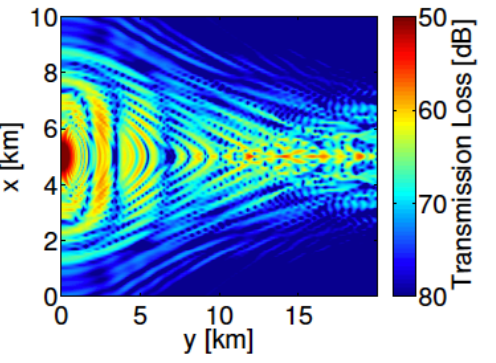

(d)

Figure 9: Horizontal cuts over the Gaussian canyon at depths of $10 \mathrm{~m} \mathrm{(a),} 35 \mathrm{~m} \mathrm{(b),} 100 \mathrm{~m}$ (c) and $150 \mathrm{~m}(\mathrm{~d})$.

\section{Bottom loss and surface roughness data collection at TREX13:}

The reflection coefficient data from the TREX experiment was analyzed to determine sediment density fluctuations shown in the left panel of Fig. 10. In this panel, the upper figure is based on historical measurements in the area [Richardson, 2005.] while the lower panel is based on the reflection measurements. Note that the density derived from the reflection measurements is much lower than those measured historically. Both models include a bathymetry based on survey results, measured sound speed profiles and an overlying mud layer. These models were used in a finite element reverberation model using a frequency centered at $500 \mathrm{~Hz}$. The difference in reverberation between the constant density model and the range dependent density derived from the reflection coefficient measurements is shown in the right panel of Fig. 10.
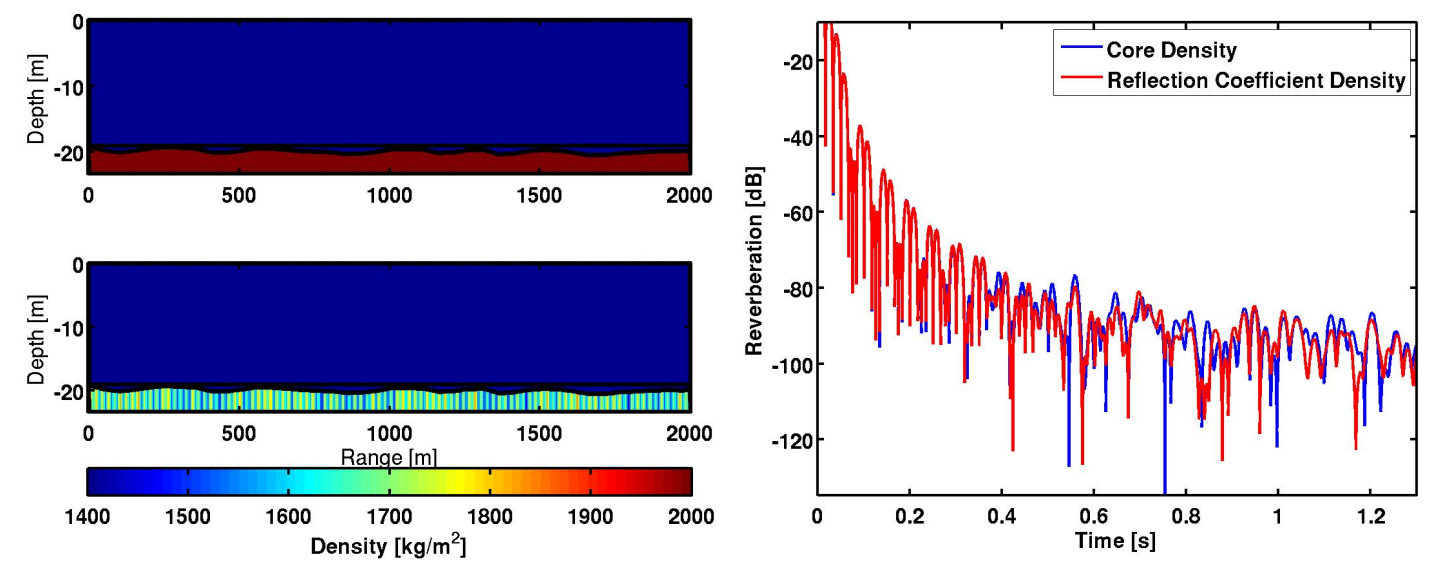


\section{Figure 10: Reverberation estimate based on finite element analysis at $500 \mathrm{~Hz}$ for the TREX experiment along the reverberation track.}

\section{IMPACT/APPLICATIONS}

The finite element reflection loss models could transition into a new high frequency and low frequency reflection loss (LFBL/HFBL) data curves for NAVO based on site-specific characteristics. The 3D LI model can be used to understand propagation and reverberation in complex environments. An understanding of normal incident reflection loss is critical to sediment characterization and mine burial prediction. The TREX13 measurements will serve as ground truth bottom loss and interface roughness measurements for reverberation modeling.

\section{RELATED PROJECTS}

Under the iPUMA and SSAM Sediment Environmental Estimation (iSSEE) program, this group is also developing sediment characterization algorithms for AUV sonars based on the measurements and models previously developed by this program. Additionally, the models developed in this research will be used to increase the fidelity of sonar trainers under the High Fidelity Active Sonar Trainer (HiFAST) program. There will be significant collaboration with Dr. Nicholas Chotiros, particularly for theoretical development of bulk acoustic/sediment modeling and laser roughness measurements.

\section{REFERENCES}

C. Eckart, The scattering of sound from the sea surface", J. Acoust. Soc. Am. 25:560-570, 1953.

J. Ogilvy, Theory of Wave Scattering from Random Rough Surfaces (Institute of Physics Publishing Limited, Bristol, England) (1991).

G.B. Deane and M.J. Buckingham. An analysis of the three-dimensiona sound field in a penetrable wedge with a stratified fluid or elastic basement. J. Acoust. Soc. Am., 93(3):1319-1328, 1993.

M. Ballard, B. Goldsberry, and M. Isakson. A three-dimensional propagation model with stepwise coupled modes. J. Comp. Acous., In Review, 2014.

D. Jackson, R. Odom, M. Boyd, and A. Ivakin. A GeoAcoustic Bottom Interaction Model (GABIM). IEEE J. Ocean Eng., 35(3) : 603-617, 2010.

K. Williams, "An effective density fluid model for acoustic propagation in sediments derived from Biot theory," J. Acoust. Soc. Am., 110(5): 2276-2281, 2001.

D. Jackson and M. Richardson, High-Frequency Sea Floor Acoustics. Springer-Verlag, New York, 2007.

A. Tolstoy, K. Smith and N. Maltsev. The SWAM'99 Workshop. J. Comp. Acoust., 9(1): 1-16, 2001.

M. D. Richardson, et al. "Characterization of the environment during SAX04: Preliminary Results," in Proc. of the 1st Int. Conf. "Underwater Acoustic Measurements: Technologies and Results, July 2005. 


\section{PUBLICATIONS}

1. M. Isakson, and N. Chotiros. Finite Element Modeling of Acoustic Scattering from Fluid and Elastic Interfaces, IEEE J. Ocean Eng. DOI 10.1109/JOE.2014.2313060 .

2. M. Isakson, B. Goldsberry and N. Chotiros. A three-dimensional, longitudinally invariant finite element model for acoustic propagation in shallow water waveguides. J. Acoust. Soc. Am., 136, EL206 (2014).

3. M. Ballard, B. Goldsberry, and M. Isakson. A three-dimensional propagation model with stepwise coupled modes. J. Comp. Acous., In Review, 2014.

4. N. Chotiros and M. Isakson. Introduction to the special issue on sediment acoustics, J. Acoust. Soc. Am., 134, 119 (2013).

5. B. Goldsberry and M. Isakson. Modeling scattering rough poroelastic surfaces using Comsol multiphysics. In Proc. 2013 COMSOL Conference in Boston. COMSOL, October 2013.

6. A. L. Bonomo, M. Isakson, and N. Chotiros. Modeling scattering rough poroelastic surfaces using Comsol multiphysics. In Proc. 2013 COMSOL Conference in Boston. COMSOL, October 2013.

\section{PRESENTATIONS}

M. Isakson, A. Bonomo and N. Chotiros. Acoustic Backscattering from Layered Interfaces using Finite Elements. In Proceedings of International Conference and Exhibition on Underwater Acoustics, Rhodes, Greece, June 2014.

M. Isakson, N. Chotiros, Acoustic scattering from ocean sediment layers with multiple rough interfaces using finite elements, J. Acoust. Soc. Am. 134, 4250 (2013).

M. Isakson, Computer modeling as teaching tool in underwater acoustics, J. Acoust. Soc. Am. 134, 4015 (2013).

M. Isakson and N. Chotiros, Modeling range dependent sediment and interface roughness effects on propagation loss with finite elements, J. Acoust. Soc. Am. 135, 2298 (2014).

M. Isakson, Highlights of the Underwater Acoustics Technical Committee at the 167th Meeting of the Acoustical Society of America, J. Acoust. Soc. Am. 135, 2181 (2014).

N. Chotiros and M. Isakson. Sediment acoustics: The need for improvement. In Proceedings of International Conference and Exhibition on Underwater Acoustics, Rhodes, Greece, June 2014.

G. Potty, J. Giard, J. Miller, B. Goldsberry and M. Isakson, Inversion of shear wave speed in coastal sediments using interface waves, J. Acoust. Soc. Am. 134, 4241 (2013).

A. Bonomo, M. Isakson and N. Chotiros, Comparison of the finite element method with perturbation theory and the small-slope approximation for acoustic scattering from one-dimensional rough poroelastic surfaces, J. Acoust. Soc. Am. 134, 4251 (2013).

M. Ballard, B. Goldsberry and M. Isakson. Three-dimensional propagation: Comparison of finite element and coupled-mode solutions, , J. Acoust. Soc. Am. 134, 4110 (2013).

N. Chotiros and M. Isakson, The high frequency environmental acoustics sediment model in the light of recent advances, J. Acoust. Soc. Am. 134, 4207 (2013).

N. Chotiros, M. Isakson, J. Piper and A. McNeese, Spatial variation of seabed acoustic bulk properties, J. Acoust. Soc. Am. 135, 2231 (2014).

A. Bonomo, M. Isakson and N. Chotiros, Acoustic scattering from a sand layer and rock substrate with rough interfaces using the finite element method, J. Acoust. Soc. Am. 135, 2298 (2014).

B. Goldsberry and M. Isakson, Modeling three-dimensional propagation in a continental shelf environment using the finite element method, J. Acoust. Soc. Am. 135, 2428 (2014).

N. Chotiros and M. Isakson, Shear wave attenuation and micro-fluidics in water-saturated sand and glass beads, J. Acoust. Soc. Am. 135, 3264 (2014). 